\title{
Systematic Evaluation and Mechanistic Investigation of Antioxidant Activity of Fullerenols Using $\beta$-Carotene Bleaching Assay
}

\author{
Hiroshi Ueno, Shizuka Yamakura, Riya S. Arastoo, Takumi Oshima, and Ken Kokubo \\ Division of Applied Chemistry, Graduate School of Engineering, Osaka University, 2-1 Yamadaoka, Suita, \\ Osaka Prefecture 565-0871, Japan \\ Correspondence should be addressed to Ken Kokubo; kokubo@chem.eng.osaka-u.ac.jp
}

Received 27 June 2014; Accepted 12 August 2014; Published 28 August 2014

Academic Editor: Naoki Kishi

Copyright (C) 2014 Hiroshi Ueno et al. This is an open access article distributed under the Creative Commons Attribution License, which permits unrestricted use, distribution, and reproduction in any medium, provided the original work is properly cited.

\begin{abstract}
Antioxidant activity of hydroxylated fullerenes, so-called fullerenols, against lipid peroxyl radical was evaluated by $\beta$-carotene bleaching assay. All samples showed moderate to high antioxidant activity (\%AOA), especially for $\mathrm{C}_{60}(\mathrm{OH})_{12}(70.1)$ and $\mathrm{C}_{60}(\mathrm{OH})_{44}$ (66.0) as compared with $8,24,26$, and 36 hydroxylated ones (31.7-62.8). The detection of the possible products was conducted in the model reaction of both fullerenols and $\mathrm{C}_{60}$ with methyl linoleate by MALDI-TOF-MS. These results suggested that the two possible mechanisms, such as $\mathrm{C}$-addition to double bonds and $\mathrm{H}$-abstraction from - $\mathrm{OH}$ groups, are involved in the present radical scavenging reaction.
\end{abstract}

\section{Introduction}

Fullerene known as "radical sponge" has been recognized as a new class of antioxidant due to its high reactivity toward radical species since its first report in 1991 [1]. Reactive oxygen species (ROS), such as superoxide, hydroxyl radical, peroxyl radicals, and nitric oxide, have such radical nature and cause damage to biomolecules, including DNA, cell, protein, and lipid, inducing various diseases. For this reason, the development of biocompatible, nontoxic, and watersoluble fullerene derivatives has been strongly demanded. In the past several years, we have evaluated the ROS radical scavenging ability as "antioxidant activity" of water-soluble $\gamma$ cyclodextrin- (CD-) bicapped $\mathrm{C}_{60}$ and polyvinylpyrrolidone(PVP-) entrapped $\mathrm{C}_{60}$ as well as the corresponding fullerene oxides $\left(\mathrm{C}_{60} \mathrm{O}_{n}\right)[2,3]$. However, their solubility in water still remains low and inevitable steric repulsion from the host compounds, such as CD and PVP, brings about undesirable interference for accurate bioassay.

Polyhydroxylated fullerenes, so-called fullerenols, have attracted much attention in view of biological, pharmaceutical, and medical applications, because of their high hydrophilicity and the low toxicity as well as the unique spherical structure with a diameter of ca. $1 \mathrm{~nm}$. In this point of view, the antioxidant activity of fullerenol has been reported in 1995 by Chiang et al. for $\mathrm{C}_{60}(\mathrm{OH})_{12}$ [4] and in 2009 by Miwa et al. for highly hydroxylated fullerenol $\mathrm{C}_{60}(\mathrm{OH})_{32}$ [5] as well as other bioactivities, such as the inhibitive effect for oxidative stress in adipocytes [6], protective effect of human keratinocytes from UV-induced cell injuries [7], and suppression of intracellular lipid accumulation [8]. In connection with the recent developments of these biological studies [9-11], new and facile synthetic procedures of highly hydroxylated water-soluble fullerenols have been reported [12-14]. However, little is known about their origin of antioxidant activity and the relationship between the activity and the number of hydroxyl groups. For the development of new application of these unique nanomaterials, the systematic investigation of the antioxidant activity of variously hydroxylated fullerenols, such as $8,10,12,24,26,36$, and 44 hydroxylated ones [15], is highly desirable to explore the antioxidant mechanism of fullerenols toward ROS (Figure 1).

The $\beta$-carotene bleaching assay for evaluating antioxidant activity is one of the common methods used in the field of food chemistry [16]. The principle of the method is based on the discoloration of yellowish color of a $\beta$-carotene solution 


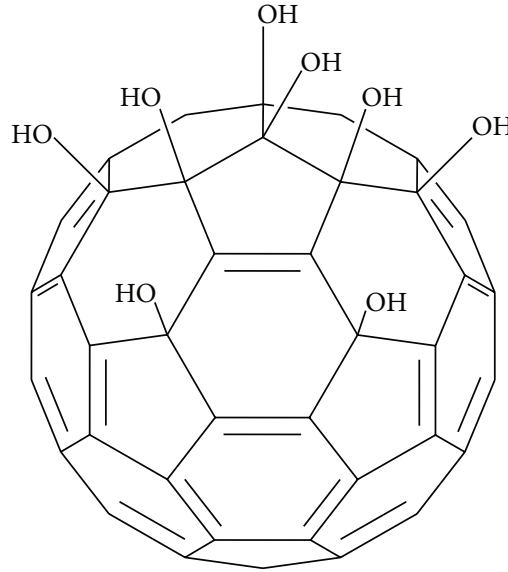

(a) $\mathrm{C}_{60}(\mathrm{OH})_{8}$

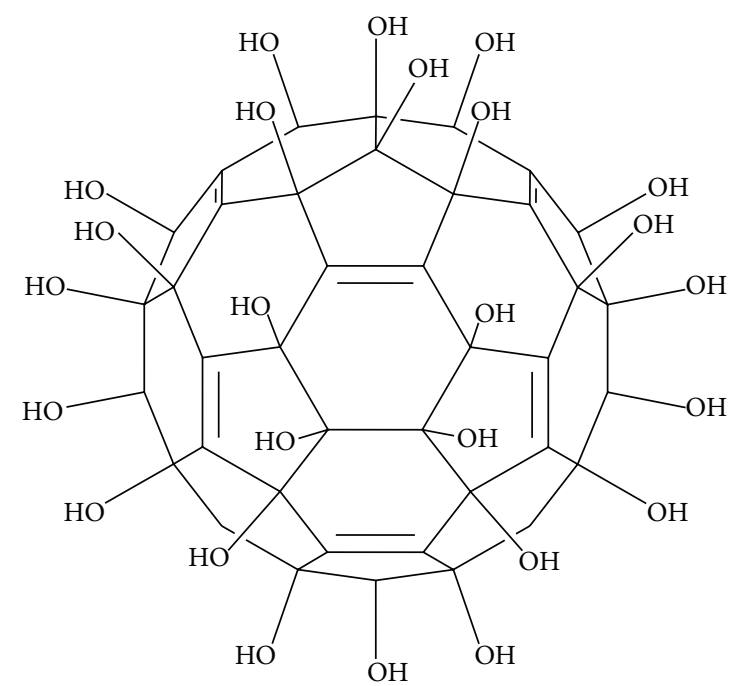

(b) $\mathrm{C}_{60}(\mathrm{OH})_{36}$

FIGURE 1: A possible isomer of fullerenols composed of a mixture of isomers and expressed by the average structures as $(\mathrm{a}) \mathrm{C}_{60}(\mathrm{OH})_{8}$ and $(\mathrm{b})$ $\mathrm{C}_{60}(\mathrm{OH})_{36}$.

due to the breaking of $\pi$-conjugation by addition reaction of lipid or lipid peroxyl radical $\left(\mathrm{L}^{\bullet}\right.$ or $\mathrm{LOO}^{\bullet}$ ) to a $\mathrm{C}=\mathrm{C}$ double bond of $\beta$-carotene. The radical species is generated from the autoxidation of linoleic acid by heating under air atmosphere. When the appropriate antioxidant is added to the solution, the discoloration can be retarded by competing reaction between $\beta$-carotene and antioxidant with the subjected radicals. The structural similarity between fullerenes and $\beta$ carotene, such as highly $\pi$-conjugated molecules, enables the accurate evaluation of antioxidant activity by this $\beta$-carotene bleaching assay in contrast to other methods like DPPH radical assay [17].

Herein, we report the systematic investigation of antioxidant activity of variously hydroxylated fullerenols with 8 , $10,12,24,26,36$, and 44 hydroxyl groups evaluated by $\beta$ carotene bleaching assay. In combination with detecting the possible products of both fullerenols and $\mathrm{C}_{60}$ with radical species generated from methyl linoleate under autoxidation condition, we propose two antioxidant mechanisms which are dependent on the number of hydroxyl groups.

\section{Materials and Methods}

2.1. Materials and Apparatuses. Fullerenols $\mathrm{C}_{60}(\mathrm{OH})_{n}(n=$ 44 and 36) were synthesized by the previously reported procedures using hydrogen peroxide $[12,13]$ and $\mathrm{C}_{60}(\mathrm{OH})_{26}$ was synthesized by the modified method with a shorter reaction time (methods $A$ and $A^{\prime}$ ). Fullerenol $\mathrm{C}_{60}(\mathrm{OH})_{\sim 24}$ prepared from $\mathrm{C}_{60} \mathrm{Br}_{24}$ was purchased from MTR Ltd. (method B). Fullerenols $\mathrm{C}_{60}(\mathrm{OH})_{n}(n=12$ and 8$)$ were synthesized by the modification of the literature method using oleum (method C) [19]. Fullerene $\mathrm{C}_{60}$ was purchased from Frontier Carbon Corporation as nanom purple ST $(99 \%)$.

$\beta$-Carotene, linoleic acid (>99\%), catechin mixture, isoflavone mixture, coenzyme Q10 (as ubiquinone-10), curcumin, and $\alpha$-lipoic acid were purchased from Wako Pure Chemical Industries, Ltd. Other reagents and organic solvents as well as pure water were all commercially available and used as received. UV-visible spectra were measured on a JASCO V-550 equipped with a thermal controller. LCMS analysis was performed on a SHIMADZU LCMS-2010EV. Matrix assisted laser desorption ionization time-of-flight mass spectra (MALDI-TOF-MS) were measured on a Bruker autoflex III.

2.2. $\beta$-Carotene Bleaching Assay. The $\beta$-carotene bleaching assay was performed according to an optimally modified procedure $[2,3]$. Chloroform solutions of $11 \mu \mathrm{L}$ of $\beta$-carotene $(1.0 \mathrm{mg} / \mathrm{mL}, 8.2 \mu \mathrm{M}), 4.4 \mu \mathrm{L}$ of linoleic acid $(0.1 \mathrm{~g} / \mathrm{mL}, 628 \mu \mathrm{M})$, and $22 \mu \mathrm{L}$ of Tween $40(0.2 \mathrm{~g} / \mathrm{mL})$ were mixed in a quartz cell equipped with a screw-on cap and then the solvent was removed in vacuo. The residual emulsion was immediately diluted with $2.4 \mathrm{~mL}$ of phosphate buffer solution (0.02 M, pH $=7.01)$, and $0.1 \mathrm{~mL}$ of antioxidant $(0-20 \mu \mathrm{M})$ in deionized water $\left(\mathrm{C}_{60}(\mathrm{OH})_{22}, 36\right.$, and 44$)$ or DMSO $\left(\mathrm{C}_{60}(\mathrm{OH})_{8}, 12\right.$, and 26$)$ was added to the diluted mixture. The solution was mixed well and heated at $50^{\circ} \mathrm{C}$ under air in a quartz cell on a UV spectrometer in order to monitor the decrease in the absorbance of $\beta$-carotene at $460 \mathrm{~nm}$.

\section{Results and Discussion}

The discoloration rate in the presence of fullerene $\left(R_{f}\right)$ is defined as (1), where $k_{\text {obs }}$ is an observed pseudo-first-order rate constant, and $k_{c}$ and $k_{f}$ are rate constants for the reaction of $\beta$-carotene and fullerene with radical species (represented by $\mathrm{LOO}^{\circ}$ ), respectively. Because the concentration of radical species must be considerably low and if it is approximated as a constant, the rate obeys a pseudo-first-order rate law with a constant of $k_{\text {obs }}$. When fullerene is absent as a control (i.e., 


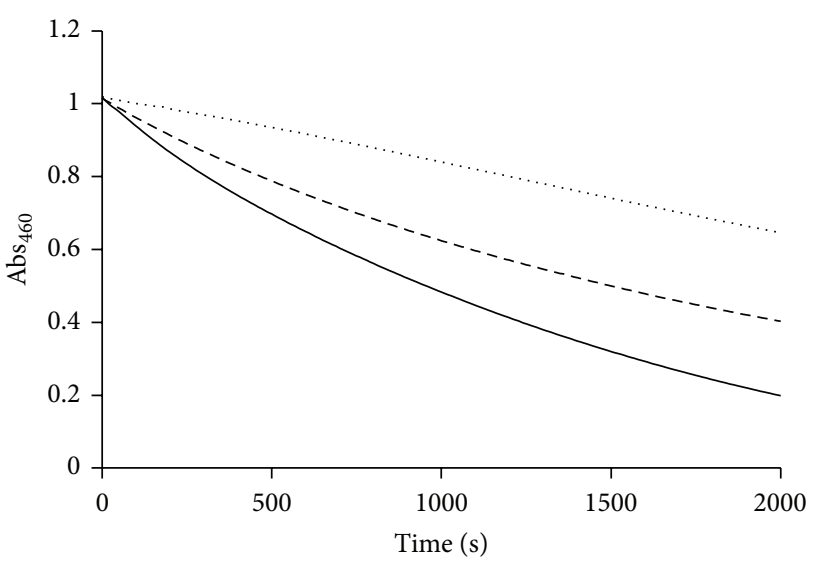

(a)

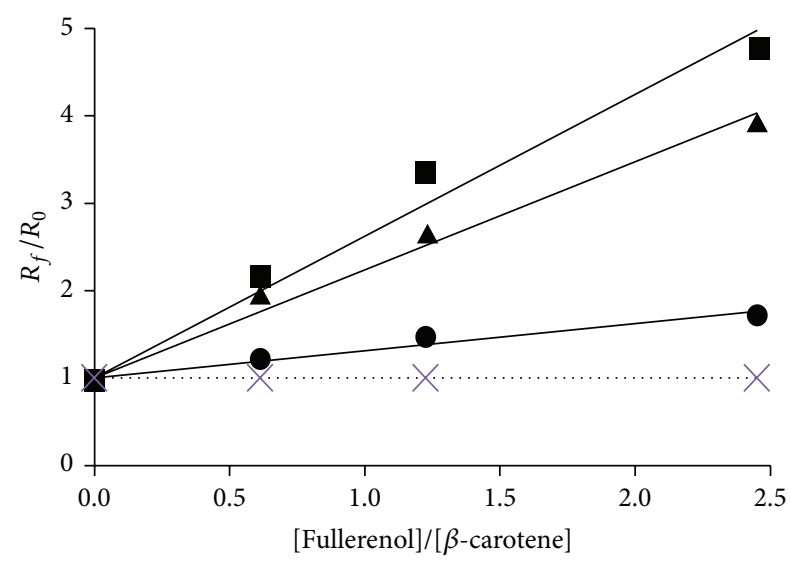

$\mathrm{C}_{60}(\mathrm{OH})_{12}$

$\Delta \mathrm{C}_{60}(\mathrm{OH})_{8}$

- $\mathrm{C}_{60}(\mathrm{OH})_{26}$

(b)

FIGURE 2: (a) Time course of the discoloration of $\beta$-carotene induced by autoxidation of linoleic acid under air at $50^{\circ} \mathrm{C}$ in the absence (solid line for control) or the presence of fullerenols (dotted line for $\mathrm{C}_{60}(\mathrm{OH})_{12}$ and dashed line for $\mathrm{C}_{60}(\mathrm{OH})_{8}$ in $10 \mu \mathrm{M}$ ) by monitoring of UV absorbance at $460 \mathrm{~nm}$. (b) Plots of the ratio of $\beta$-carotene bleaching (discoloration) rates in the presence $\left(R_{f}\right)$ or absence $\left(R_{0}\right)$ of fullerenol $R_{f} / R_{0}$ versus the ratio of concentration [fullerenol] $/[\beta$ carotene] for various fullerenols: marked by square for $\mathrm{C}_{60}(\mathrm{OH})_{12}$, triangle for $\mathrm{C}_{60}(\mathrm{OH})_{8}$, and circle for $\mathrm{C}_{60}(\mathrm{OH})_{26}$. The slope of each linear regression line corresponds to the relative radical scavenging rate constant $k_{\text {rel }}$ of fullerenols relative to $\beta$-carotene $\left(=k_{f} / k_{c}\right)$. The dotted horizontal line indicates the value in the absence of antioxidant as a control $\left(R_{f}=R_{0}\right.$ at any concentration; $\left.k_{\text {rel }}=0\right)$.

[fullerene] $=0$ ), the discoloration rate of $\beta$-carotene is defined as $R_{0}$. Consider

$$
\begin{aligned}
R_{f}= & \frac{-d[\beta \text {-carotene }]}{d t}=k_{\mathrm{obs}}[\beta \text {-carotene }] \\
= & k_{c}[\beta \text {-carotene }] \\
& \times\left(\frac{k_{c}[\beta \text {-carotene }]}{k_{c}[\beta \text {-carotene }]+k_{f}[\text { fullerene }]}\right)\left[\text { LOO }^{*}\right] .
\end{aligned}
$$

TABLE 1: The relative rate constant $\left(k_{\text {rel }}\right)$ and antioxidant activity (\%AOA) of fullerenols ${ }^{\mathrm{a}}$.

\begin{tabular}{lccc}
\hline Compound & Method $^{\mathrm{b}}$ & $k_{\text {rel }}$ & \%AOA at $10 \mu \mathrm{M}$ \\
\hline $\mathrm{C}_{60}(\mathrm{OH})_{44}$ & $\mathrm{~A}$ & 1.54 & 66.0 \\
$\mathrm{C}_{60}(\mathrm{OH})_{36}$ & $\mathrm{~A}^{\prime}$ & 0.80 & 52.7 \\
$\mathrm{C}_{60}(\mathrm{OH})_{24}$ & $\mathrm{~B}$ & 0.68 & 46.0 \\
$\mathrm{C}_{60}(\mathrm{OH})_{26}$ & $\mathrm{~A}^{\prime}$ & 0.31 & 31.7 \\
$\mathrm{C}_{60}(\mathrm{OH})_{12}$ & $\mathrm{C}$ & 1.62 & 70.1 \\
$\mathrm{C}_{60}(\mathrm{OH})_{8}$ & $\mathrm{C}$ & 1.24 & 62.8 \\
$\mathrm{C}_{60}{ }^{\mathrm{c}}$ & {$[3]$} & 0.79 & 50.0 \\
\hline
\end{tabular}

${ }^{\mathrm{a}}$ The reaction was conducted in anoxic conditions.

${ }^{\mathrm{b}}$ Preparation method described in Section 2.

${ }^{\mathrm{c}} \mathrm{PVP}$ was used as a water solubilizer.

The $\beta$-carotene bleaching assay was carried out by previously reported method [2]. The decrease in absorbance of $\beta$ carotene is plotted as $\ln \left[\left(\mathrm{Abs}_{0}\right) /\left(\mathrm{Abs}_{t}\right)\right]$ versus reaction time that gave a linear regression line after a short presteady state (Figure 2(a)), consistent with the above approximation of the reaction as a pseudo-first-order kinetics (1).

By the plot of discoloration rate ratio $R_{f} / R_{0}$ to the various molar ratio of [fullerene $] /[\beta$-carotene] as shown in Figure $2(\mathrm{~b})$, the ratio of rate constants $k_{f} / k_{c}$, which means the relative reactivity of fullerene to $\beta$-carotene (defined as $k_{\text {rel }}$ ), can be obtained as the slope of a linear line with the intercept of 1 as expressed by

$$
\begin{aligned}
\frac{R_{f}}{R_{0}} & =\frac{k_{\text {obs }} \text { of fullerene }}{k_{\text {obs }} \text { of control }}=\frac{k_{c}[\beta \text {-carotene }]+k_{f}[\text { fullerene }]}{k_{c}[\beta \text {-carotene }]} \\
& =1+\frac{k_{f}}{k_{c}} \frac{[\text { fullerene }]}{[\beta \text {-carotene }]}, \quad\left(\frac{k_{f}}{k_{c}}=k_{\text {rel }}\right) .
\end{aligned}
$$

The $R_{f} / R_{0}$ plots for $\mathrm{C}_{60}(\mathrm{OH})_{8}, \mathrm{C}_{60}(\mathrm{OH})_{12}$, and $\mathrm{C}_{60}(\mathrm{OH})_{26}$ exhibited that the highest $k_{\text {rel }}$ value of 1.62 (i.e., 1.62 times reactive toward the present radical species relative to $\beta$-carotene) was observed for $\mathrm{C}_{60}(\mathrm{OH})_{12}$. The $k_{\text {rel }}$ values as well as $\% \mathrm{AOA}$ at $10 \mu \mathrm{M}$ of various fullerenols were summarized in Table 1 . The antioxidant activity expressed using \%AOA was defined by (3). The fullerenols having higher $k_{\text {rel }}$ values showed higher values of \%AOA. The $\% \mathrm{AOA}$ is convenient to express the antioxidant activity using the value in the range from 0 (low) to 100 (high). However, it should be noted that the value of \% AOA is concentration-dependent and the value of $k_{\text {rel }}$ is not. Consider

$$
\% \mathrm{AOA}=\frac{\left(k_{\mathrm{obs}} \text { of control }\right)-\left(k_{\mathrm{obs}} \text { of sample }\right)}{k_{\mathrm{obs}} \text { of control }} \times 100 .
$$

Fullerenols $\mathrm{C}_{60}(\mathrm{OH})_{n}$ having ca. $10(n=8$ and 12) or ca. 40 (36 and 44) hydroxyl groups showed somewhat high antioxidant activity as compared with those having ca. 25 (24 and 26). Lowly hydroxylated fullerene (ca. 10) showed high antioxidant activity probably because of the remaining relatively high $\pi$-conjugation in $\mathrm{C}=\mathrm{C}$ double bonds, such as high HOMO and low LUMO, which is favourable for the 
TABLE 2: The relative rate constant $\left(k_{\text {rel }}\right)$ and antioxidant activity (\%AOA) of naturally occurring antioxidants ${ }^{\mathrm{a}, \mathrm{b}}$.

\begin{tabular}{lcc}
\hline Compound & $k_{\text {rel }}$ & \%AOA at $10 \mu \mathrm{M}$ \\
\hline Catechin & 4.95 & 80.2 \\
$\mathrm{C}_{60}(\mathrm{OH})_{44}$ & 1.54 & 66.0 \\
$\beta$-Carotene & 1.00 & - \\
Isoflavone & 0.68 & 35.6 \\
Coenzyme Q10 & 0.50 & 29.1 \\
Curcumin & 0.26 & 17.7 \\
$\alpha$-Lipoic acid & 0.10 & 7.4 \\
\hline
\end{tabular}

${ }^{\mathrm{a}}$ The reaction was conducted in anoxic conditions.

${ }^{\mathrm{b}}$ Data from [18].<smiles>CCCCC/C=C/C=C/CCCCCCCC(=O)OC</smiles><smiles>CCCCC/C=C/C([O-])/C=C/CCCCCCCC(=O)OC</smiles>

FIGURE 3: Structure of methyl linoleate (ML) and its peroxyl radical (MLOO*).

efficient molecular orbital interaction with the radical SOMO. Therefore, the activity decreased with the increasing number of hydroxyl groups, thus decreasing $\pi$-conjugation, up to ca. 25 . However, surprisingly, the activity again increased with the increasing number of hydroxyl groups up to ca. 40 as highly hydroxylated ones. The present result suggests that the antioxidant mechanism of highly hydroxylated fullerenes may be different from those of lowly hydroxylated ones (vide infra).

For the comparison, the antioxidant activities of representative naturally occurring antioxidants measured by the same procedure were summarized in Table 2 [18]. Catechin showed the extremely high $k_{\text {rel }}$ and \%AOA values among those tested. Fullerenol $\mathrm{C}_{60}(\mathrm{OH})_{44}$ also exhibited relatively high radical scavenging activity, slightly higher even than $\beta$-carotene, while curcumin and $\alpha$-lipoic acid showed poor values in the present $\beta$-carotene bleaching assay.

General antioxidants are mainly categorized into three types according to their antioxidant mechanism, such as (i) electron donating type (reductant like ascorbic acid), (ii) hydrogen donating type (antioxidant having reactive hydrogen atom like phenolic -OH group of catechin), and (iii) radical trapping type (antioxidant having highly conjugated $\mathrm{C}=\mathrm{C}$ double bonds like $\beta$-carotene) [20]. To investigate the antioxidant mechanism of fullerene, the reaction of $\mathrm{C}_{60}$ with methyl linoleate (ML) under autoxidation condition [21], heating with 300 equivalent excess of ML in toluene at $70^{\circ} \mathrm{C}$ for 3 days, was conducted as a model reaction. Because of the technical problems on solubility and mass detectability, the employment of linoleic acid failed. Both by MALDI-TOF-MS and by LC-MS with APCI negative mode analyses of the crude reaction mixture, the peroxyl

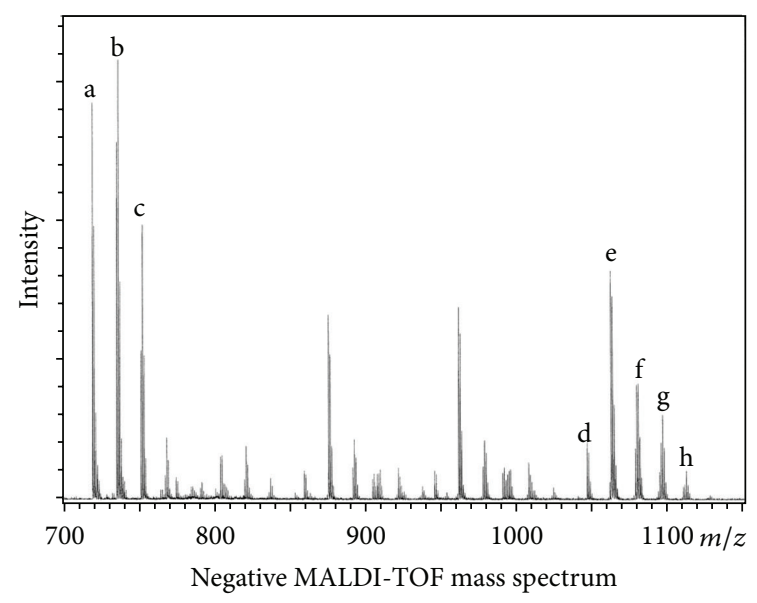

(a)

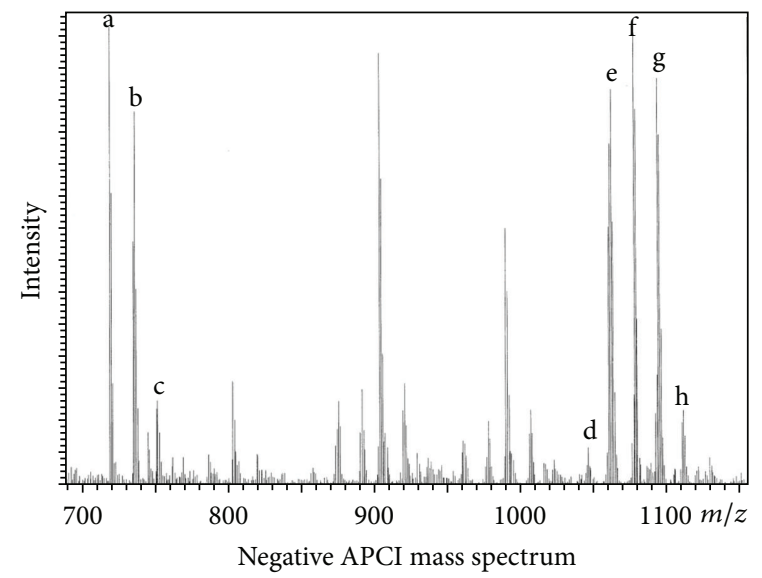

\begin{tabular}{ccc}
\hline Peak & $m / z$ (MALDI/APCI) & Ion \\
\hline $\mathrm{a}$ & $720 / 720$ & $\mathrm{C}_{60}{ }^{-}$ \\
$\mathrm{b}$ & $737 / 737$ & $\mathrm{C}_{60}(\mathrm{OH})^{-}$ \\
$\mathrm{c}$ & $753 / 753$ & $\mathrm{C}_{60} \mathrm{O}(\mathrm{OH})^{-}$ \\
$\mathrm{d}$ & $1045 / 1046$ & $\mathrm{C}_{60}(\mathrm{OOML})^{-}$ \\
$\mathrm{e}$ & $1061 / 1062$ & $\mathrm{C}_{60} \mathrm{O}(\mathrm{OOML})^{-}$ \\
$\mathrm{f}$ & $1078 / 1078$ & $\mathrm{C}_{60} \mathrm{O}_{2}(\mathrm{OOML})^{-}$ \\
$\mathrm{g}$ & $1095 / 1095$ & $\mathrm{C}_{60} \mathrm{O}_{3}(\mathrm{OOML})^{-}$ \\
$\mathrm{h}$ & $1111 / 1111$ & $\mathrm{C}_{60} \mathrm{O}_{4}(\mathrm{OOML})^{-}$ \\
\hline
\end{tabular}

(b)

Figure 4: Mass spectra of the crude product on the reaction of $\mathrm{C}_{60}$ with an excess amount of methyl linoleate by heating under air.

radical of methyl linoleate $\left(\mathrm{MLOO}^{\circ}\right)$ was revealed to give fullerene multioxides $\left(\mathrm{C}_{60} \mathrm{O}_{n}\right)$ and their radical addition products $\left[\mathrm{C}_{60}(\mathrm{O})_{n}(\mathrm{OOML})_{m}\right]$ along with their fragment peaks (Figures 3 and 4). This could be a part of evidence for a radical trap mechanism of fullerene $\mathrm{C}_{60}$. On the other hand, no peaks derived from $\mathrm{MLOO}^{\circ}$ were obtained in the reaction of $\mathrm{C}_{60}(\mathrm{OH})_{8}$ with $\mathrm{ML}$ by mass and NMR spectroscopy. Although it failed to detect the product in this case, the disappearance of mass peaks corresponding to the starting $\mathrm{C}_{60}(\mathrm{OH})_{8}$, which were observed before the reaction, implied that the fullerenol reacted with ML. 


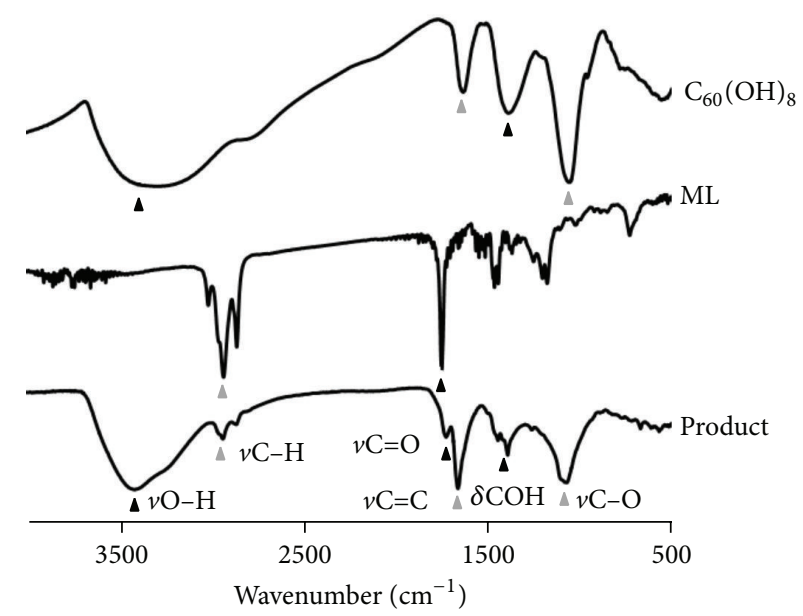

FIGURE 5: IR spectra of the crude product on the reaction of fullerenol $\mathrm{C}_{60}(\mathrm{OH})_{8}$ with methyl linoleate $(\mathrm{ML})$ under autoxidation condition along with those of the starting materials.

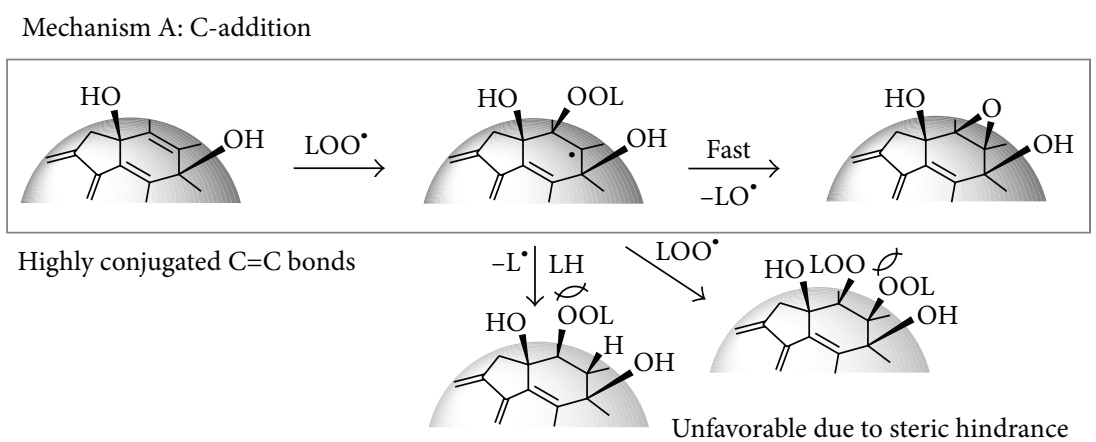

(a)

Mechanism B: H-abstraction

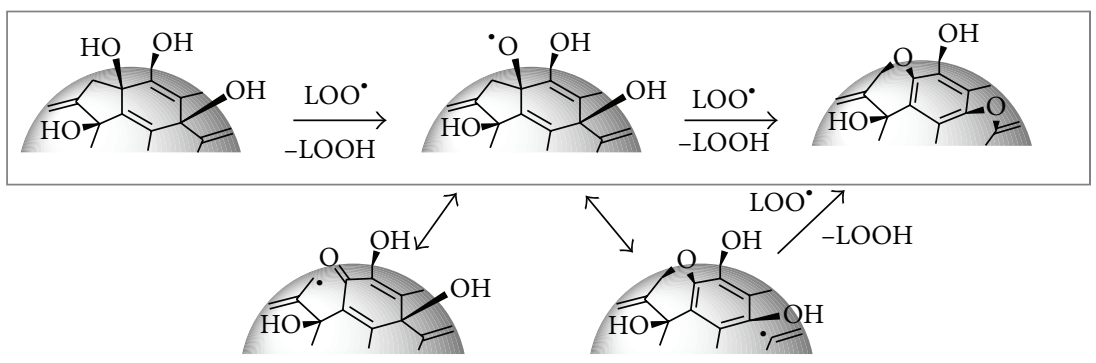

Fast C-C cleavage due to higher strain

(b)

Figure 6: Possible mechanisms for lipid peroxyl radical $\left(\mathrm{LOO}^{\circ}\right)$ scavenging by fullerenols $\mathrm{C}_{60}(\mathrm{OH})_{n}$ : (a) addition to C=C double bonds for less hydroxylated fullerenes and (b) $\mathrm{H}$-abstraction from -OH group for highly hydroxylated ones.

Instead of the failed mass analysis, the reaction product of fullerenol $\mathrm{C}_{60}(\mathrm{OH})_{8}$ with $\mathrm{ML}$ was analysed by IR spectroscopy (Figure 5). Even after reprecipitation of the product from diethyl ether/hexane $=9 / 1$ followed by Florisil column chromatography with an eluent of THF, the small peak at ca. $1700 \mathrm{~cm}^{-1}$ assigned for $\nu \mathrm{C}=\mathrm{O}$ was observed along with the peaks at ca. $2900 \mathrm{~cm}^{-1}$ assigned for $\nu \mathrm{C}-\mathrm{H}$. These signals may appear by the addition of $\mathrm{MLOO}^{\circ}$ which has an ester moiety or by the hydrogen abstraction from hydroxyl group with the subsequent carbonyl group formation (vide infra).

By considering the above results, we proposed two possible radical scavenging mechanisms of fullerenols as shown in Figure 6. One is "C-addition" type, which includes the peroxyl radical addition to a conjugated $\mathrm{C}=\mathrm{C}$ double bond (mechanism A), and the other is "H-abstraction" type, which includes hydrogen atom abstraction from - $\mathrm{OH}$ group and the 
subsequent skeletal rearrangement of fullerenyl cage forming ether bridge (mechanism B). Lowly hydroxylated fullerenols $\mathrm{C}_{60}(\mathrm{OH})_{n}(n=$ ca. 10$)$ which have enough $\pi$-conjugated double bonds probably favour the "C-addition" mechanism similar to the pristine $\mathrm{C}_{60}$. By contrast, highly hydroxylated fullerenols $\mathrm{C}_{60}(\mathrm{OH})_{n}(n=\mathrm{ca}$. 40) seem to be relatively difficult to undergo the $\mathrm{C}$-addition of $\mathrm{MLOO}^{\circ}$ because they have less and unreactive double bonds in addition to the larger steric hindrance from the crowded hydroxyl groups. The latter mechanism is the same as catechin (polyphenol) type and it is supported by the fact that some fullerenols have acidic (similar to phenolic) hydroxyl groups. Because highly hydroxylated fullerenols have larger strain on fullerenyl cage due to the conversion of many sp $\mathrm{s}^{2}$ carbons into $\mathrm{sp}^{3}$ carbons by hydroxylation, $\mathrm{H}$-abstraction may be followed by the subsequent skeletal rearrangement on $\mathrm{C}_{60}$ cage to release the strain energy, forming some ether bridge. Fullerenols $\mathrm{C}_{60}(\mathrm{OH})_{n}$ $(n=$ ca. 24$)$ result in poor antioxidant activity probably due to the lack of both effects.

Finally, we also measured the antioxidant activity of several alcohols and phenols. Under the same condition of $\beta$-carotene bleaching assay, ethanol, $t$-butyl alcohol, benzyl alcohol, allyl alcohol, phenol, and $p$-bromophenol did not show antioxidant activity in spite of the existence of hydroxyl groups and unsaturated structures. The result clearly suggests the importance of high conjugation and distorted structure of fullerenols for the antioxidant activity in $\beta$-carotene bleaching assay.

\section{Conclusions}

In conclusion, we systematically evaluated the antioxidant activity of variously hydroxylated fullerenols by $\beta$-carotene bleaching assay. The antioxidant activity \%AOA was varied from $32 \%$ to $70 \%$ by changing the number of hydroxyl groups and both lowly hydroxylated $\mathrm{C}_{60}(\mathrm{OH})_{12}(70.1 \%)$ and highly hydroxylated $\mathrm{C}_{60}(\mathrm{OH})_{44}(66.0 \%)$ showed relatively high antioxidant activity. The obtained relative radical scavenging rate of fullerene $k_{\text {rel }}$ toward radical species derived from linoleic acid under autoxidation condition indicated that these fullerenols reacted 1.62 and 1.54 times faster than $\beta$-carotene, respectively. By the product analysis using the model reaction of $\mathrm{C}_{60}$ and methyl linoleate under autoxidation condition, we detected several mass peaks of radical scavenged fullerene derivatives as well as the IR spectra. These results suggest that the high $\pi$-conjugation and the strained structure of fullerenol are responsible for the high radical scavenging reactivity and thus we proposed two possible antioxidant mechanisms, such as $\mathrm{C}$-addition type and $\mathrm{H}-$ abstraction type, which are dependent on the number of hydroxyl groups.

\section{Conflict of Interests}

The authors declare that there is no conflict of interests regarding the publication of this paper.

\section{Acknowledgments}

This work was supported by Health Labor Sciences Research Grants from MHLW, Japan. The authors thank Dr. H. Aoshima (Vitamin C60 BioResearch Corporation) for helpful discussion.

\section{References}

[1] P. J. Krusic, E. Wasserman, P. N. Keizer, J. R. Morton, and K. F. Preston, "Radical reactions of $\mathrm{C}_{60}$," Science, vol. 254, no. 5035, pp. 1183-1185, 1991.

[2] H. Takada, K. Kokubo, K. Matsubayashi, and T. Oshima, "Antioxidant activity of supramolecular water-soluble fullerenes evaluated by $\beta$-carotene bleaching assay," Bioscience, Biotechnology and Biochemistry, vol. 70, no. 12, pp. 3088-3093, 2006.

[3] K. Matsubayashi, T. Goto, K. Togaya, K. Kokubo, and T. Oshima, "Effects of pin-up oxygen on [60] fullerene for enhanced antioxidant activity," Nanoscale Research Letters, vol. 3, no. 7, pp. 237241, 2008.

[4] L. Y. Chiang, F.-J. Lu, and J.-T. Lin, "Free radical scavenging activity of water-soluble fullerenols," Journal of the Chemical Society, Chemical Communications, no. 12, pp. 1283-1284, 1995.

[5] S. Kato, H. Aoshima, Y. Saitoh, and N. Miwa, "Highly hydroxylated or $\gamma$-cyclodextrin-bicapped water-soluble derivative of fullerene: the antioxidant ability assessed by electron spin resonance method and $\beta$-carotene bleaching assay," Bioorganic and Medicinal Chemistry Letters, vol. 19, no. 18, pp. 5293-5296, 2009.

[6] Y. Saitoh, L. Xiao, H. Mizuno et al., "Novel polyhydroxylated fullerene suppresses intracellular oxidative stress together with repression of intracellular lipid accumulation during the differentiation of OP9 preadipocytes into adipocytes," Free Radical Research, vol. 44, no. 9, pp. 1072-1081, 2010.

[7] Y. Saitoh, A. Miyanishi, H. Mizuno et al., "Super-highly hydroxylated fullerene derivative protects human keratinocytes from UV-induced cell injuries together with the decreases in intracellular ROS generation and DNA damages," Journal of Photochemistry and Photobiology B, vol. 102, no. 1, pp. 69-76, 2011.

[8] Y. Saitoh, H. Mizuno, L. Xiao, S. Hyoudou, K. Kokubo, and N. Miwa, "Polyhydroxylated fullerene $\mathrm{C}_{60}(\mathrm{OH})_{44}$ suppresses intracellular lipid accumulation together with repression of intracellular superoxide anion radicals and subsequent PPAR $\gamma 2$ expression during spontaneous differentiation of OP9 preadipocytes into adipocytes," Molecular and Cellular Biochemistry, vol. 366, no. 1-2, pp. 191-200, 2012.

[9] G. D. Nielsen, M. Roursgaard, K. A. Jensen, S. S. Poulsen, and S. T. Larsen, "In vivo biology and toxicology of fullerenes and their derivatives," Basic \& Clinical Pharmacology \& Toxicology, vol. 103, no. 3, pp. 197-208, 2008.

[10] J. Gao, Y. Wang, K. M. Folta et al., "Polyhydroxy fullerenes (fullerols or fullerenols): beneficial effects on growth and lifespan in diverse biological models," PLoS ONE, vol. 6, no. 5, Article ID e19976, 8 pages, 2011.

[11] Z. Chen, L. Ma, Y. Liu, and C. Chen, "Applications of functionalized fullerenes in tumor theranostics," Theranostics, vol. 2, no. 3, pp. 238-250, 2012.

[12] K. Kokubo, S. Shirakawa, N. Kobayashi, H. Aoshima, and T. Oshima, "Facile and scalable synthesis of a highly hydroxylated water-soluble fullerenol as a single nanoparticle," Nano Research, vol. 4, no. 2, pp. 204-215, 2011. 
[13] K. Kokubo, K. Matsubayashi, H. Tategaki, H. Takada, and T. Oshima, "Facile synthesis of highly water-soluble fullerenes more than half-covered by hydroxyl groups," ACS Nano, vol. 2, no. 2, pp. 327-333, 2008.

[14] H. Ueno, K. Kokubo, E. Kwon, Y. Nakamura, N. Ikuma, and T. Oshima, "Synthesis of a new class of fullerene derivative $\mathrm{Li}^{+} @ \mathrm{C}_{60} \mathrm{O}^{-}(\mathrm{OH})_{7}$ as a "Cation-encapsulated anion nanoparticle”'” Nanoscale, vol. 5, pp. 2317-2321, 2013.

[15] G. Zhang, Y. Liu, D. Liang, L. Gan, and Y. Li, "Facile synthesis of isomerically pure fullerenols and formation of spherical aggregates from $\mathrm{C}_{60}(\mathrm{OH})_{8}$," Angewandte Chemie International Edition, vol. 49, pp. 5293-5295, 2010.

[16] M. S. Al-Saikhan, L. R. Howard, and J. C. Miller Jr., "Antioxidant activity and total phenolics in different genotypes of potato (Solanum tuberosum, L.)," Journal of Food Science, vol. 60, pp. 341-347, 1995.

[17] A. Djordjevic, J. M. Canadanovic-Brunet, M. VojinovicMiloradov, and G. Bogdanovic, "Antioxidant properties and hypothetic radical mechanism of fullerenol $\mathrm{C}_{60}(\mathrm{OH})_{24}$," Oxidation Communications, vol. 27, no. 4, pp. 806-812, 2004.

[18] H. Aoshima, K. Togaya, T. Goto et al., "Evaluation of antioxidant activity of fullerenes and their inhibition effects on photodegradation of cosmetic ingredients," Journal of Japanese Cosmetic Science Society, vol. 33, pp. 149-154, 2009.

[19] L. Y. Chiang, L.-Y. Wang, J. W. Swirczewski, S. Soled, and S. Cameron, "Efficient synthesis of polyhydroxylated fullerene derivatives via hydrolysis of polycyclosulfated precursors," Journal of Organic Chemistry, vol. 59, no. 14, pp. 3960-3968, 1994.

[20] G. W. Burton and K. U. Ingold, “ $\beta$-Carotene: an unusual type of lipid antioxidant," Science, vol. 224, no. 4649, pp. 569-573, 1984.

[21] K. Fukuzumi, N. Ikeda, and M. Egawa, "Phenothiazine derivatives as new antioxidants for the autoxidation of methyl linoleate and their reaction mechanisms," Journal of the American Oil Chemists'Society, vol. 53, no. 10, pp. 623-627, 1976. 

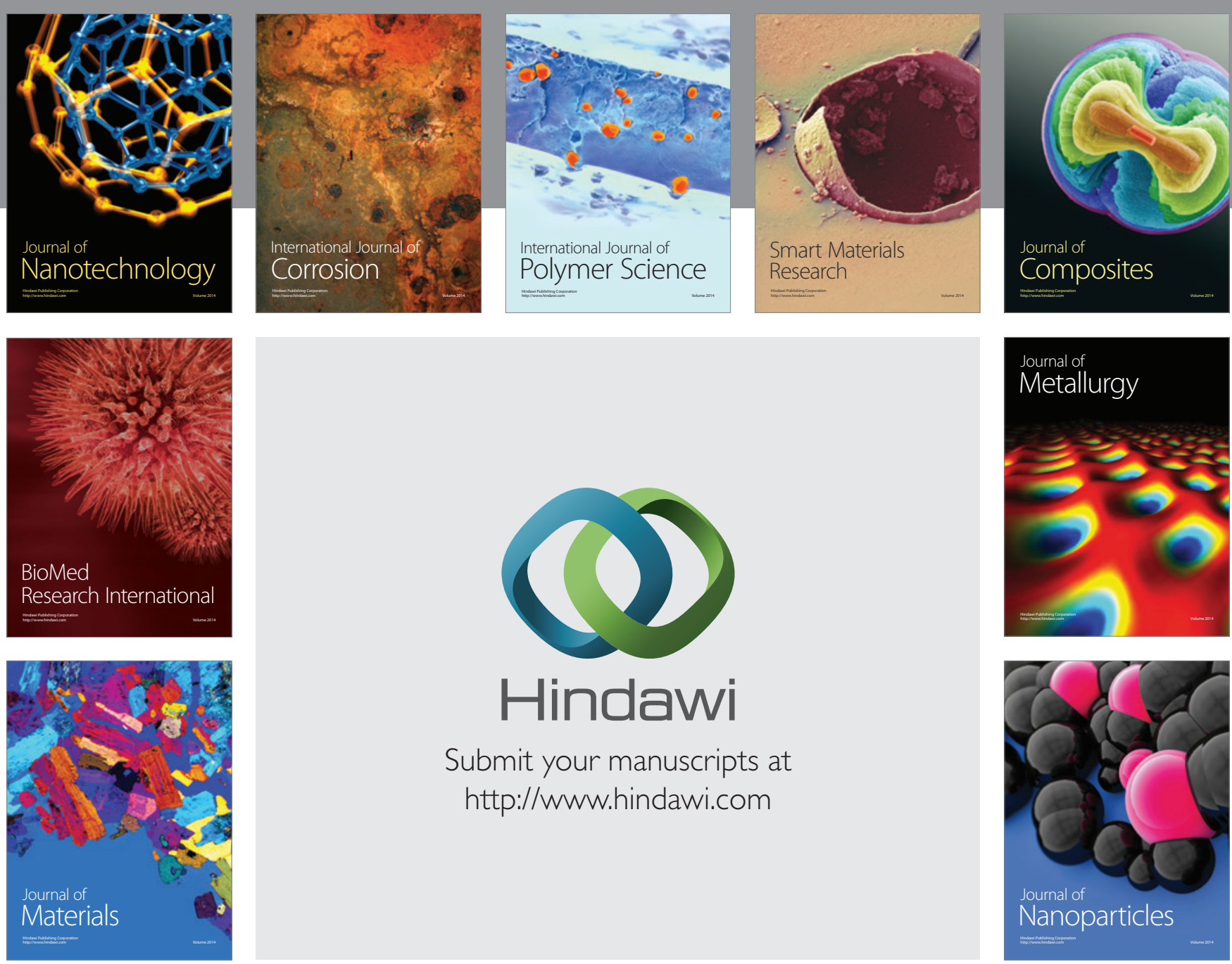

Submit your manuscripts at http://www.hindawi.com
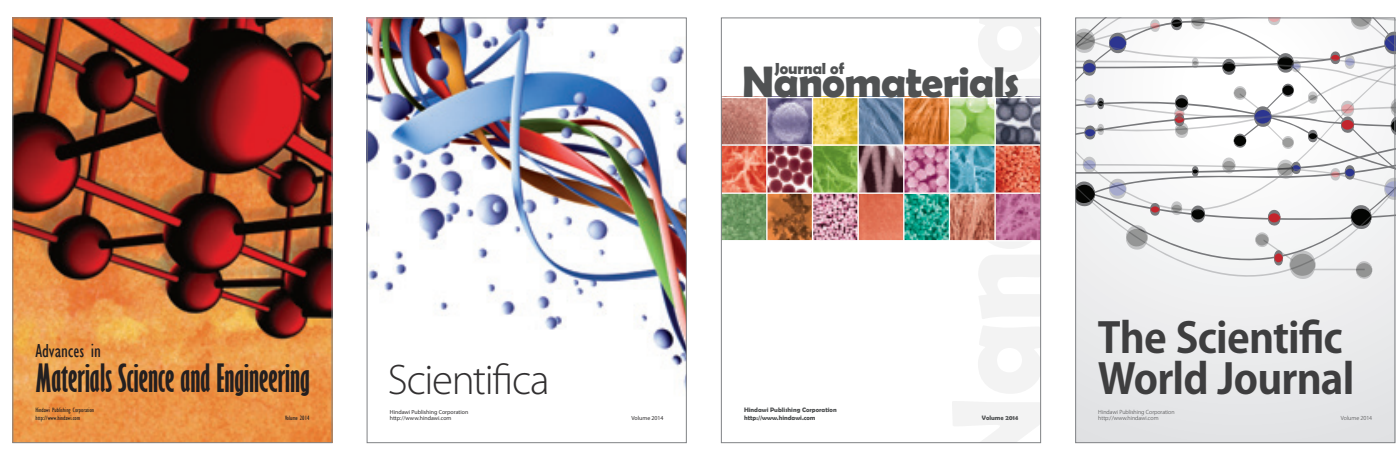

\section{The Scientific World Journal}
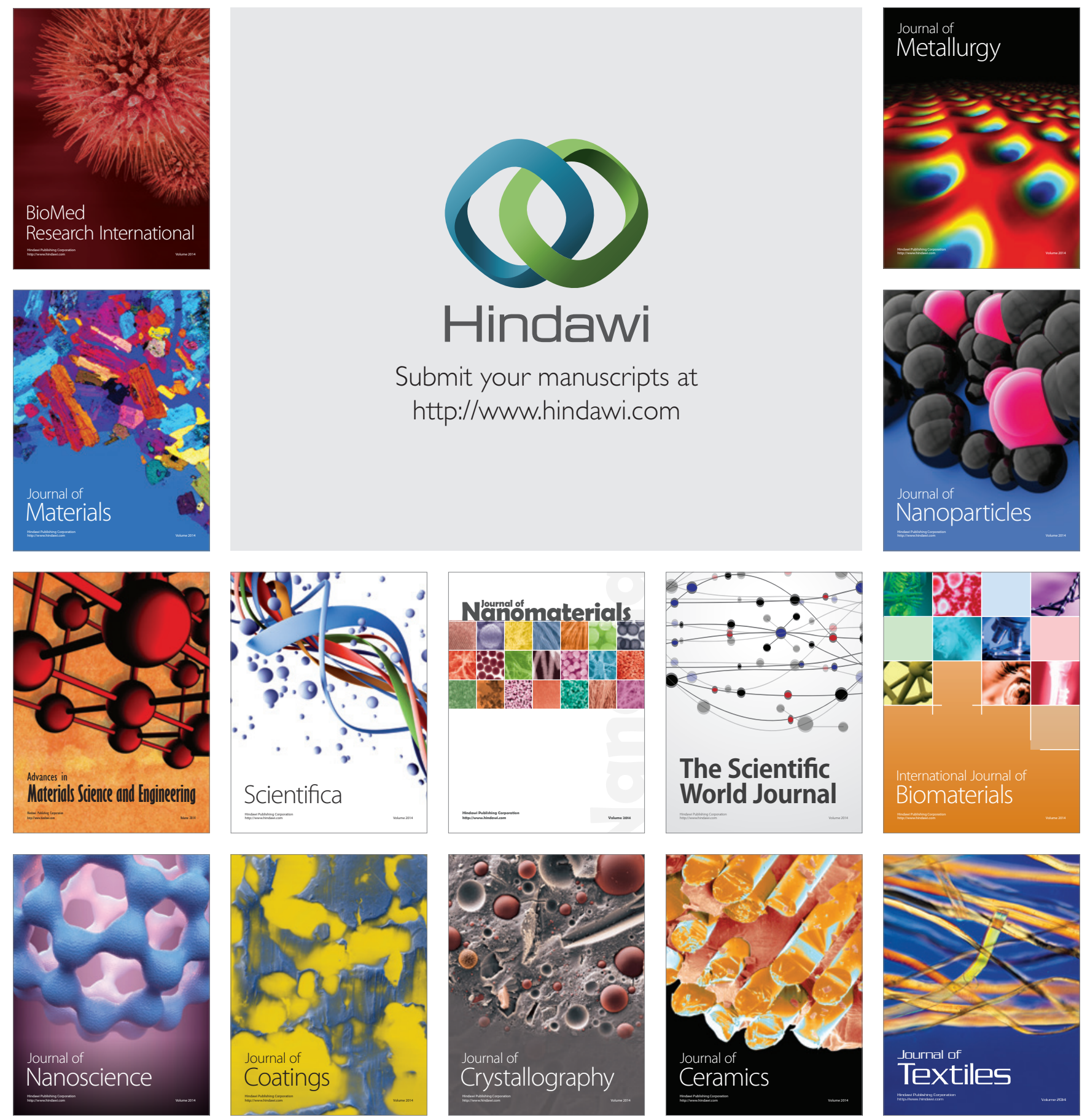